\title{
Especialização Inteligente à Escala Urbana: Análise Dirigida ao Diagnóstico do PDM da Cidade do Porto
}

\author{
T. Sá Marques (a), H. Santos (b), D. Ribeiro (c), P. Ribeiro (d) \\ (a) Centro de Estudos de Geografia e Ordenamento do Território (CEGOT). Departamento de Geografia, Faculdade de Letras da Universidade do \\ Porto, teresasamarques@gmail.com \\ (b) Centro de Estudos de Geografia e Ordenamento do Território (CEGOT). Faculdade de Letras da Universidade do Porto, hfcs75@hotmail.com \\ (c) Faculdade de Letras da Universidade do Porto, mrcotgeo@gmail.com \\ (d) Centro de Estudos de Geografia e Ordenamento do Território (CEGOT)/ Faculdade de Letras da Universidade do Porto, \\ paularibeiro82@gmail.com
}

\section{Resumo}

A política de especialização inteligente, tal como foi preconizada pela União Europeia (UE) dirige-se à escala regional. No entanto, à escala local, existem instrumentos de política de desenvolvimento do território que são estruturais para o desenvolvimento e o planeamento e o ordenamento do território. Nomeadamente nos territórios de grande densidade, como é o caso da cidade do Porto, o papel de liderança que desempenham face à região em que se inserem e o peso considerável que têm nas dinâmicas socioeconómicas da região leva-nos a considerar que os instrumentos de política local não devem ser ignorados no processo de construção e aplicação das políticas de especialização inteligente. A presente comunicação apresenta parte da análise desenvolvida para o PDM do concelho do Porto que se centra na exploração de atividades económicas enquadráveis nos domínios de especialização inteligente definidos pela RIS3 Norte e respetiva espacialização intraurbana.

Palavras chave: Estratégia de Especialização Inteligente, escala local, PDM, Porto.

\section{INTRODUÇÃO}

A política de especialização inteligente, tal como foi preconizada pela União Europeia (UE), dirige-se à escala regional. No entanto, à escala local, existem instrumentos de política de desenvolvimento que são estruturais para o desenvolvimento e o planeamento e o ordenamento do território. Nomeadamente nos territórios de grande densidade, como é o caso da cidade do Porto, o papel de liderança que desempenham face à região em que se inserem e o peso considerável que têm nas dinâmicas socioeconómicas da região leva-nos a considerar que os instrumentos de política local não devem ser ignorados no processo de construção e aplicação das políticas de especialização inteligente.

A presente comunicação uma parte do diagnóstico desenvolvido para o PDM do concelho do Porto, nomeadamente no que corresponde à identificação das atividades económicas (estabelecimento) enquadradas nos domínios de especialização inteligente definidos para a RIS3 Norte, o seu peso na economia da cidade (PIB, VAB, exportações e emprego) e a sua distribuição na cidade do Porto.

Começando por apresentar os argumentos teóricos que sustentam esta abordagem à escala local do conceito de especialização inteligente, apresenta-se a metodologia que suporta a subsequente análise da estrutura económica do concelho enquadrável na RIS3 da região Norte e prossegue-se cartografando a sua espacialização na cidade, na procura de tendência para a clusterização. A terminar apresentam-se os contributos para a tomada de decisão em matéria de políticas públicas de ordenamento do território das atividades económicas, que poderão nomeadamente condicionar os usos do solo, nomeadamente no sentido de contribuir para uma implementação mais eficaz da estratégia de especialização inteligente. Apresentam-se ainda algumas limitações relativas à implementação da estratégia de especialização inteligente (RIS3) à escala local.

\section{ESTRATÉGIA DE ESPECIALIZAÇÃO INTELIGENTE: DAS POLÍTICAS REGIONAIS ÀS POLÍTICAS LOCAIS DE DESENVOLVIMENTO ECONÓMICO}

A estratégia de especialização inteligente é atualmente uma realidade no território da União Europeia. 
Concebida originalmente enquanto conceito de política setorial, coloca vários desafios no momento de operacionalização no âmbito das políticas de desenvolvimento territorial e coesão regional (McCann \& Ortega-Argilés, 2013). Dirigida sobretudo à escala regional (McCann \& Ortega-Argilés, 2013; Sandu, 2012; Gulc, 2015; Kempton, 2015; Balland, Boschma, Crespo, \& Rigby, 2018), ainda que enquadrado à escala nacional (IAPMEI; FCT; ANI; COMPETE, 2014), as orientações de política que emanam da União Europeia explicitam a necessidade de uma abordagem bottom-up, que reúna, entre outros atores, as autoridades locais para trabalharem em conjunto no sentido de estabelecerem estratégias de longo prazo na aplicação dos fundos comunitários (EuropeanCommission, 2017). No entanto, estas orientações ignoram o contributo dos instrumentos de política local (planos estratégicos e planos diretores municipais) para a construção e implementação das estratégias de especialização inteligente.

As primeiras avaliações desta fase inicial de implementação da especialização inteligente apontam, entre outros, o estrangulamento provocado pela falta de pré-condições na economia local que possibilitem a sua implementação (Capello \& Kroll, 2016) ou a dificuldade de aplicar este conceito na grande diversidade de regiões rurais (Naldi, Nilsson, Westlund, \& Wixe, 2015). Isto é, nem sempre o conceito de especialização inteligente encaixa nos territórios à escala regional, o que aponta para a necessidade de redirecionar o foco, até agora muito centrado nas indústrias, para estratégias de desenvolvimento de base territorial (Capello \& Kroll, 2016).

Para além da reorientação da estratégia de especialização inteligente na direção das políticas de base territorial (Barca, McCann, \& Rodríguez-Pose, 2012), este apelo ao território pode passar por uma maior atenção à escala local, nomeadamente através do envolvimento dos instrumentos de política elaborados à escala das áreas metropolitanas, das comunidades urbanas ou dos municípios, na construção, articulação e implementação das estratégias de especialização inteligente.

Alguns trabalhos recentes demonstram que o conceito de especialização inteligente pode ser incorporado nos instrumentos de política pública desenvolvidos à escala metropolitana (Marques \& Queirós, AMP 2020 Crescimento Inteligente, 2017) ou à escala urbana (Novosák, Hájek, Zahradník, \& Nekolová, 2013; Maximilian, Bieringer, Knaupp, Wittemaier, \& Wruck, 2016), nomeadamente na formulação de planos estratégicos de desenvolvimento económico.

No caso particular das grandes cidades, estas são os locais onde se colocam os principais desafios e ocorrem os principais processos de desenvolvimento económico e social (ESPON, 15/12/2010). Caracterizadas por uma elevada densidade populacional e um forte fluxo de pessoas (residentes, trabalhadores, visitantes), as cidades são facilitadoras do aumento e da diversificação da procura e possibilitam o acesso a um conjunto de infraestruturas e externalidades fundamentais aos processos de produção de bens e à prestação de serviços, nomeadamente ao capital financeiro, ao capital humano ou ao acesso a fornecedores, entre muitos outros (Boschma, 2010). A cidade é catalisadora de crescimento económico e de desenvolvimento (Marques, 2004; Beaverstock, Faulconbridge, \& Hoyler, 2011; Mendes, 2011), concentrando uma proporção crescente de atividades socioeconómicas, em que a proximidade e a densidade são potenciadoras. A concentração de atividades económicas atrai, por seu turno, novas atividades económicas necessárias para servir a concentração de pessoas e de negócios existentes (CE, março 2014; Nijkamp \& Kourtit, 2013). Em geral, as cidades são motores da economia, espaços de inovação, de competitividade, de cooperação e de concentração de capital humano e social.

No caso concreto do Porto, esta é a cidade com um papel liderante no desenvolvimento económico da Área Metropolitana do Porto (Marques \& Queirós, 2017; Marques \& Santos, 2013; Santos \& Marques, 2013), da região do Noroeste de Portugal (Ribeiro \& Ferrão, Noroeste Global, 2014), e, conjuntamente com Lisboa, é um dos dois motores do desenvolvimento económico de Portugal (Ribeiro, Moura, \& Chorincas, 2015; Marques, Santos, \& Ribeiro, 2016; DGT, 2018). Assim, no momento de, à escala local, selecionar um concelho para explorar a aplicação do conceito de estratégia de especialização inteligente, a cidade do Porto surge como um bom candidato para este ensaio.

Hoje, os PDM são instrumentos de política pública, em primeiro lugar de natureza estratégica e só depois de orientação e regulação dos usos dos solos (Lei n. ${ }^{\circ}$ 31/2014, de 30 de maio). Nesse sentido, é de grande importância elaborar um diagnóstico estratégico que instrua as orientações de política territorial que vão condicionar os usos dos solos. Neste âmbito, o desenvolvimento económico tem de ser uma matéria central neste instrumento de gestão estratégica do território.

A comunicação identifica a estrutura económica enquadrada nos domínios de especialização inteligente definidos para a RIS3-Norte (CCDRN, 2014) e a respetiva distribuição espacial no concelho do Porto. A comunicação estrutura-se da seguinte forma: começa-se por apresentar a metodologia utilizada, seguindo-se uma análise detalhada dos resultados em termos de stocks e distribuição territorial. 


\section{METODOLOGIA}

A estratégia de especialização inteligente para a região Norte (RIS3) identifica oito domínios prioritários de especialização e a respetiva classificação das atividades económicas (CAE) que se enquadram em cada um dos domínios de especialização inteligente. Seguindo esta classificação, identificaram-se as CAE das atividades instaladas no concelho do Porto (quadro 1). De seguida, para cada domínio de especialização inteligente, identifica-se o tecido económico instalado no concelho do Porto, analisa-se a estrutura etária dos estabelecimentos e cartografa-se a respetiva distribuição dos estabelecimentos tendo em vista analisar o padrão da distribuição territorial.

Esta análise suportou-se numa base de dados georreferenciada de estabelecimentos e empresas, localizados no concelho do Porto (à data de 31 de janeiro de 2017), com dados sobre a identificação, localização, atividade e situação económica, referentes ao exercício em 2015/2016. A cartografia temática desenvolvida representa a distribuição espacial das atividades e do emprego, através método de cálculo da densidade Kernel de pontos. Apresentam-se, para cada distribuição, dois modelos, um contendo os valores escalares da distribuição de densidades, e um conceptual, mais simplificado, que demonstra os grandes locais de concentração.

$\mathrm{Na}$ análise dos dados, começa-se por uma visão de conjunto, e prossegue-se com uma análise focalizada em cada domínio de especialização inteligente.

Quadro 1 - Domínios de especialização inteligente da RIS3 Norte

\begin{tabular}{|c|c|c|c|c|}
\hline Domínio & Descrição do Domínio & \multicolumn{2}{|c|}{$\begin{array}{l}\text { CAE (identificados para cada domínio da especialização inteligente } \\
\text { da Região Norte) }\end{array}$} & $\begin{array}{l}\text { Classificação das } \\
\text { Atividades }\end{array}$ \\
\hline $\begin{array}{l}\text { Recursos do } \\
\text { Mar e } \\
\text { Economia }\end{array}$ & $\begin{array}{l}\text { Estabelecimento de relações de articulação } \\
\text { entre engenharias aplicadas (civil, mecânica, } \\
\text { naval, robótica, energia, biociências e tecnolo- } \\
\text { gias de informação, materiais), recursos do } \\
\text { mar (vento, ondas, algas, praias, etc) e ativida- } \\
\text { des económicas que os valorizem (construção } \\
\text { naval, produção de energia em offshore, cons- } \\
\text { trução de plataformas, turismo náutico, bio- } \\
\text { combustiveis, alimentação e aquacultura em } \\
\text { offshore, etc ). }\end{array}$ & $\begin{array}{l}\text { 03111-Pesca marítima } \\
\text { 03112-Apanha de algas outros } \\
\text { produtos do mar } \\
\text { 03121-Pesca águas interiores } \\
\text { 0321-Aquicultura em águas } \\
\text { salgadas e salobras } \\
\text { 0322-Aquicultura águas doces } \\
\text { 10201-Preparação prod. pesca e } \\
\text { aquicultura } \\
\text { 10202-Congelação prod. pesca e } \\
\text { aquicultura } \\
\text { 10203-Cons. prod. pesca e } \\
\text { aquicultura em azeite, e outros } \\
\text { óleos vegetais e outros molhos } \\
\text { 10204-Salga, secagem e outras } \\
\text { act. transf. prod. da pesca e } \\
\text { aquicultura } \\
\text { 2511-Fabr. estruturas constru- } \\
\text { ções metálicas } \\
\text { 2561-Tratamento e revestimen- } \\
\text { to metais } \\
\text { 2711-Fabr. motores, geradores e } \\
\text { transformadores elétricos } \\
\text { 2811-Fabr. motores e turbinas, } \\
\text { exceto motores para aeronaves, } \\
\text { automóveis e motociclos } \\
\text { 30111-Constr. embarcações } \\
\text { metálicas e estruturas flutuantes, } \\
\text { exceto de recreio e desporto }\end{array}$ & 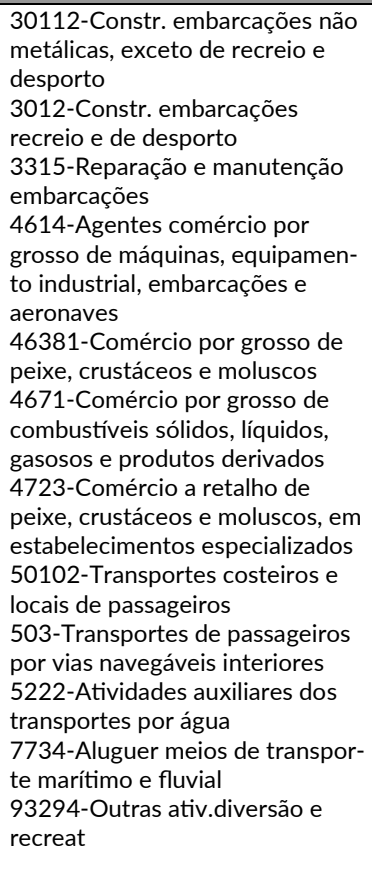 & $\begin{array}{l}\text { Construção Metálica e } \\
\text { Construção Naval } \\
\text { Atividades de Desporto } \\
\text { e Lazer } \\
\text { Transportes e Logística } \\
\text { Agricultura, Agroali- } \\
\text { mentar e Pescas e } \\
\text { Conservas } \\
\text { Comércio por grosso } \\
\text { Comércio a retalho e } \\
\text { Restauração } \\
\text { Máquinas e Equipamen- } \\
\text { tos elétrico } \\
\text { Serviços às Empresas }\end{array}$ \\
\hline $\begin{array}{l}\text { Capital Huma- } \\
\text { no e Serviços } \\
\text { Especializados }\end{array}$ & $\begin{array}{l}\text { Promoção de competências acumuladas na } \\
\text { área das TIC (em particular, no desenv. de } \\
\text { aplicações multimédia e na programação e } \\
\text { eng. de sistemas), para o desenvolvimento de } \\
\text { soluções de e-government, a desmaterializa- } \\
\text { ção de processos e, em associação com a } \\
\text { reconversão de capital humano, o aproveita- } \\
\text { mento das tendências para operações de } \\
\text { Nearshore Outsourcing (centros de engenha- } \\
\text { ria, de serv. partilhados e de contacto). }\end{array}$ & 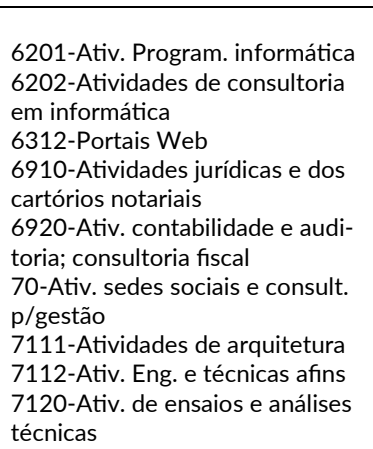 & $\begin{array}{l}\text { 721-I\&D das ciências físicas e } \\
\text { naturais } \\
\text { 722-I\&D das ciências sociais e } \\
\text { humanas } \\
\text { 731-Publicidade } \\
\text { 741-Atividades de design } \\
\text { 743-Atividades de tradução e } \\
\text { interpretação } \\
\text { 749-Outras at. consultoria, cien- } \\
\text { tíficas, técnicas e similares, n.e. } \\
\text { 821-Atividades de serviços } \\
\text { administrativos e de apoio } \\
\text { 822-Atividades dos centros de } \\
\text { chamadas }\end{array}$ & $\begin{array}{l}\text { Serviços às Empresas } \\
\text { Construção e Engenha- } \\
\text { ria } \\
\text { TIC, Indústria e Serviços } \\
\text { Investigação e Desen- } \\
\text { volvimento } \\
\text { Indústrias Criativas }\end{array}$ \\
\hline
\end{tabular}


Quadro 7 - Domínios de especialização inteligente da RIS3 Norte (continuação).

\begin{tabular}{|c|c|c|c|c|}
\hline Domínio & Descrição do Domínio & \multicolumn{2}{|c|}{$\begin{array}{l}\text { CAE (identificados para cada domínio da especialização inteligente } \\
\text { da Região Norte) }\end{array}$} & $\begin{array}{l}\text { Classificação das Ativi- } \\
\text { dades }\end{array}$ \\
\hline $\begin{array}{l}\text { Cultura, Cria- } \\
\text { ção e Moda }\end{array}$ & $\begin{array}{l}\text { Exploração do potencial das indústrias criati- } \\
\text { vas (sobretudo nas áreas de design e arquite- } \\
\text { tura), de novos materiais e de tecnologias de } \\
\text { produção inovadoras, na criação de novas } \\
\text { vantagens competitivas em setores ligados à } \\
\text { produção de bens de consumo com uma forte } \\
\text { componente de design (design based consu- } \\
\text { mer goods), nomeadamente o têxtil e vestuá- } \\
\text { rio, calçado, acessórios, mobiliário, joalharia, } \\
\text { etc. }\end{array}$ & $\begin{array}{l}\text { 1310-Prep. e fiação de fibras } \\
\text { têxteis } \\
1330-\text { Acabamento de têxteis } \\
1392-\text { Fabr. artigos têxteis confe- } \\
\text { cionados, exceto vestuário } \\
1396-\text { Fabr. têxteis para uso } \\
\text { técnico e industrial } \\
1411-\text { Confeção vestuário em } \\
\text { couro } \\
1413-\text { Confeção outro vestuário } \\
\text { exterior } \\
1419-\text { Confeção outros artigos e } \\
\text { acessórios vestuário } \\
1431-\text { Fabr. meias e similares de } \\
\text { malha } \\
1520-\text { Indústria do calçado } \\
1621-\text { Fabr. folheados e painéis à } \\
\text { base de madeira } \\
16293-\text { Ind. preparação da corti- } \\
\text { ça } \\
1811-\text { Impressão de jornais } \\
22191-\text { Fabr. componentes de } \\
\text { borracha para calçado } \\
2341-\text { Fabr. artigos cerâmicos de } \\
\text { uso doméstico e ornamental }\end{array}$ & $\begin{array}{l}\text { 25991-Fabr. louça metálica e } \\
\text { artigos de uso doméstico } \\
\text { 3102-Fabr. mobiliário de cozinha } \\
\text { 3213-Fabr. bijutarias } \\
\text { 5811-Edição de livros } \\
\text { 5814-Edição de revistas e outras } \\
\text { pub. periódicas } \\
\text { 5912-Atividades técnicas de pós } \\
\text {-produção para... } \\
\text { 5914-Projeção de filmes e ví- } \\
\text { deos } \\
\text { 6010-Atividades rádio } \\
\text { 6201-Atividades programação } \\
\text { informática } \\
\text { 6391-Atividades agências de } \\
\text { notícias } \\
\text { 7311-Agências publicidade } \\
\text { 7420-Atividades fotográficas } \\
\text { 9001-Atividades das artes do } \\
\text { espetáculo } \\
\text { 9003-Criação artística e literária } \\
\text { 9523-Rep.o calçado e artigos } \\
\text { couro } \\
\text { 9525-Rep. Relógios,artigos } \\
\text { joalharia }\end{array}$ & $\begin{array}{l}\text { Têxtil, Vestuário e } \\
\text { Calçado } \\
\text { Indústrias Criativas } \\
\text { TIC, Indústria e Serviços } \\
\text { Serviços às empresas } \\
\text { Madeira, Cortiça, Mobi- } \\
\text { liário } \\
\text { Serviços Pessoais } \\
\text { Produtos metálicos e } \\
\text { Mecânica ligeira } \\
\text { Cerâmicas e Outros } \\
\text { materiais de construção } \\
\text { Outros }\end{array}$ \\
\hline $\begin{array}{l}\text { Indústrias da } \\
\text { Mobilidade e } \\
\text { Ambiente }\end{array}$ & $\begin{array}{l}\text { Aproveitamento das competências científicas } \\
\text { nas áreas das tecnologias de produção e dos } \\
\text { materiais, potenciadas pelos contratos de } \\
\text { fornecimento com a Airbus e Embraer, para a } \\
\text { promoção do upgrade das indústrias de com- } \\
\text { ponentes de automóveis e de moldes, tendo } \\
\text { em vista o fornecimento de clientes mais } \\
\text { exigentes nas especificações técnicas, nomea- } \\
\text { damente na área da aeronáutica. }\end{array}$ & $\begin{array}{l}\text { 13962-Fabr. têxteis para uso } \\
\text { técnico e industrial, n.e. } \\
\text { 20592-Fabr. produtos químicos } \\
\text { auxiliares para uso industrial } \\
\text { 2211-Fabr. pneus e câmaras-de- } \\
\text { ar; reconstrução de pneus } \\
\text { 2442-Obtenção e primeira } \\
\text { transformação alumínio } \\
\text { 2511-Fabr. estruturas de cons- } \\
\text { truções metálicas } \\
\text { 2561-Tratam. e revestim. metais } \\
\text { 2562-Atividades de mecânica } \\
\text { geral }\end{array}$ & 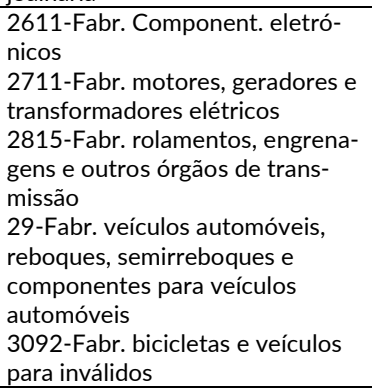 & $\begin{array}{l}\text { Const. Metálica e } \\
\text { Const. Naval } \\
\text { Máq. uso geral e setori- } \\
\text { al } \\
\text { Material de Transporte } \\
\text { - Automóvel e Diverso } \\
\text { Fundição, Siderurgia e } \\
\text { Metalurgia } \\
\text { Química Diversa } \\
\text { Máq. e Equip. elétrico } \\
\text { TIC, Indústria e Serviços } \\
\text { Têxtil, Vestuário e } \\
\text { Calçado }\end{array}$ \\
\hline $\begin{array}{l}\text { Ciências da } \\
\text { Vida e Saúde }\end{array}$ & $\begin{array}{l}\text { Consolidação das dinâmicas de articulação } \\
\text { entre a investigação regional (nomeadamente, } \\
\text { ao nível da eng.de tecidos, do cancro, das } \\
\text { neurociências e do desenv. das técnicas cirúr- } \\
\text { gicas) e as empresas nas indústrias e serv. na } \\
\text { área da saúde em sentido amplo } \\
\text { (farmacêutica, dispositivos médicos, prestação } \\
\text { de serviços saúde, turismo de saúde e bem- } \\
\text { estar e cosmética). }\end{array}$ & $\begin{array}{l}\text { 21-Fabricação de produtos } \\
\text { farmacêuticos de base e de } \\
\text { preparações farmacêuticas } \\
4646 \text {-Comércio por grosso de } \\
\text { produtos farmacêuticos } \\
4773-\text { Comércio a retalho de } \\
\text { produtos farmacêuticos, em } \\
\text { estabelecimentos especializados }\end{array}$ & $\begin{array}{l}\text { 325-Fabricação de instrumentos } \\
\text { e material médico-cirúrgico } \\
4774-\text { Comércio a retalho de } \\
\text { produtos médicos e ortopédicos, } \\
\text { em estabelecimentos especiali- } \\
\text { zados } \\
\text { 86-Atividades de saúde humana }\end{array}$ & $\begin{array}{l}\text { Serviços Coletivos } \\
\text { Comércio a retalho e } \\
\text { Restauração } \\
\text { Comércio por grosso } \\
\text { Indústria Farmacêutica } \\
\text { e Instrumentação Médi- } \\
\text { ca }\end{array}$ \\
\hline
\end{tabular}


Quadro 7 - Domínios de especialização inteligente da RIS3 Norte (continuação).

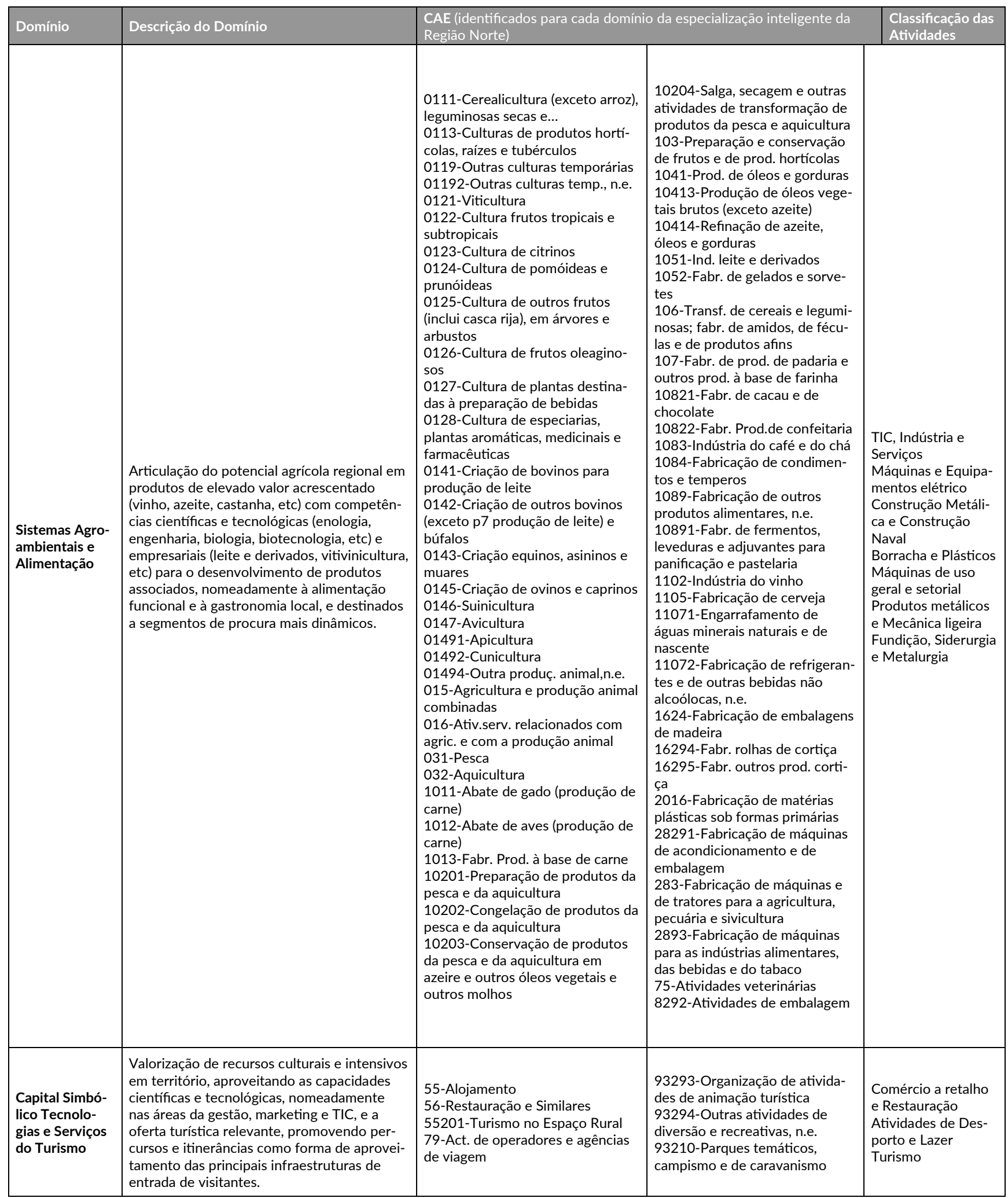


Quadro 7 - Domínios de especialização inteligente da RIS3 Norte (continuação).

\begin{tabular}{|c|c|c|c|c|}
\hline Domínio & Descrição do Domínio & \multicolumn{2}{|c|}{$\begin{array}{l}\text { CAE (identificados para cada domínio da especialização inteligente da } \\
\text { Região Norte) }\end{array}$} & $\begin{array}{l}\text { Classificação das } \\
\text { Atividades }\end{array}$ \\
\hline $\begin{array}{l}\text { Sistemas Avan- } \\
\text { çados de Pro- } \\
\text { dução }\end{array}$ & $\begin{array}{l}\text { Desenvolvimento de fileiras associadas às } \\
\text { Tecnologias de Largo Espectro (Key Enabling } \\
\text { Technologies), nomeadamente os Sistemas } \\
\text { de Produção Avançados (Advanced Manu- } \\
\text { facturing Systems), Nanotecnologias, Materi- } \\
\text { ais e TICE, conjugando a existência de capa- } \\
\text { cidades e infraestruturas cientificas e tecno- } \\
\text { lógicas, e de setores utilizadores relevantes, } \\
\text { através do reforço do tecido empresarial } \\
\text { existente (no caso das tecnologias de produ- } \\
\text { ção e das TICE) ou da criação de novas em- } \\
\text { presas (sobretudo na área da nanotecnologia } \\
\text { e da produção de novos materiais). }\end{array}$ & 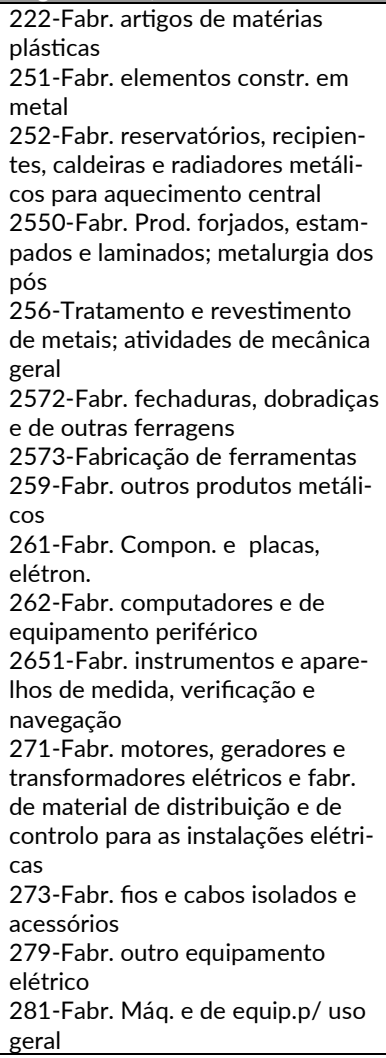 & 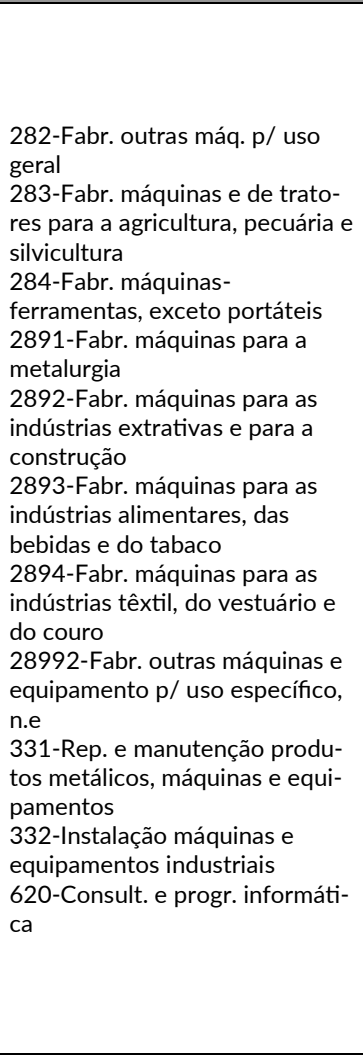 & $\begin{array}{l}\text { TIC, Indústria e } \\
\text { Serviços } \\
\text { Máquinas e Equipa- } \\
\text { mentos elétrico } \\
\text { Construção Metáli- } \\
\text { ca e Construção } \\
\text { Naval } \\
\text { Borracha e Plásticos } \\
\text { Máquinas de uso } \\
\text { geral e setorial } \\
\text { Produtos metálicos } \\
\text { e Mecânica ligeira } \\
\text { Fundição, Siderurgia } \\
\text { e Metalurgia }\end{array}$ \\
\hline
\end{tabular}

Fonte: Elaboração própria a partir do documento RIS3-Região Norte

\section{DOMÍNIOS DE ESPECIALIZAÇÃO INTELIGENTE: ANÁLISE À ESCALA DO CONCELHO DO PORTO}

\subsection{O Porto no contexto regional e nacional}

O concelho do Porto representa a área central de um ecossistema económico existente no Noroeste, uma das duas macrorregiões do país, que se distinguem pela capacidade de criação de valor e riqueza e pela concentração de emprego e atividades económicas.

Este dinamismo empresarial pode ser avaliado a partir do número de sociedades constituídas, que tem vindo a aumentar progressivamente desde 2009 até 2016 (à exceção de 2012) a nível regional e metropolitano (Gráfico 1). Em 2016, o concelho do Porto concentrava $28 \%$ do número de sociedades constituídas ${ }^{1}$ da $A M P$ e era o segundo concelho do país com maior número de constituições (5\% do total), a seguir ao concelho de Lisboa (16\%). Apesar do número de dissoluções ter aumento entre 2009 e 2016 no concelho do Porto, à semelhança da AMP e da Região Norte, os valores registados são inferiores aos nascimentos. O tecido económico do concelho demonstra capacidade de resiliência aos efeitos da crise, patente no progressivo aumento taxa de sobrevivência das empresas (um indicador que mede a proporção de empresas que sobreviviam dois anos após serem criadas). Assim, o Porto passou de uma taxa de sobrevivência de $50 \%$ em 2000 , para $58 \%$ em 2015 , enquanto o país passou de $49 \%$ para $61 \%$.

A evolução do valor acrescentado bruto demonstra os efeitos da crise económica. No período entre 2007 e 2012, o valor do VAB gerado no concelho do Porto registou uma forte quebra (-21\%), acima dos valores nacio-

\footnotetext{
${ }^{1}$ Constituição de Pessoas Coletivas e Entidades Equiparadas por Escritura Pública. Os valores apresentados incluem apenas a indústria, construção e serviços (secções $\mathrm{C}$ a O, exceto administração pública (secção L) da CAE Rev.2 e secções B a S, exceto administração pública (secção O) da CAE Rev.3. O INE disponibiliza os dados do número de nascimentos das empresas (pessoas singulares e coletivas), mas apenas à NUT 3.
} 
nais (-18\%) e regionais (-14\% na Região Norte e $-18 \%$ na AMP). A partir de 2012, a criação de riqueza aumentou e em 2016 o Porto era o concelho com maior capacidade de geração de riqueza na Área Metropolitana do Porto, representando $23 \%$ do valor total do VAB gerado. A nível nacional, o Porto era o terceiro concelho do país com maior riqueza criada, ultrapassado pelo concelho de Lisboa e Oeiras (Gráfico 2).

Entre o ano de 2007 e 2016, o valor das exportações de bens e produtos a nível nacional e regional evoluíram de forma positiva, registando uma quebra em 2009, em consequência dos efeitos de crise económicofinanceira (Gráfico 3). A partir desse ano verificou-se um aumento progressivo das exportações (acima dos 50\%). Apesar de ter registado uma variação positiva das suas exportações entre 2007 e 2016, as exportações do conceIho do Porto apresentam um comportamento diferenciado. Até 2012, as exportações geradas pela base económica do Porto cresceram 123\%, no entanto de 2013 a 2016, as exportações quase estgnaram (cresceram 0,7\%). Em 2016, o Porto só gerou $2 \%$ das exportações nacionais e $9 \%$ da área metropolitana, ficando atrás dos concelhos da Maia (13\%), de Vila Nova de Gaia (13\%) e de Santa Maria da Feira (11\%).

A disponibilidade e a qualificação do capital humano constituem recursos fundamentais para a competitividade dos territórios e para os processos de crescimento económico. Neste sentido, torna-se pertinente avaliar a capacidade de atratividade do concelho do Porto enquanto polo de emprego, de forma a garantir a existência de stocks e a renovação do seu mercado de trabalho.

O concelho do Porto apesar de ter registado uma diminuição do pessoal ao serviço entre 2007 e 2015 ($9 \%$ ), representava, em 2015, 22\% do pessoal ao serviço da AMP e 4\% a nível nacional. A análise das qualificações do capital humano, no concelho do Porto, revela um modelo de emprego cada vez mais qualificado, patente no aumento do pessoal ao serviço com ensino superior (entre 2007 e 2015, o aumento foi de 31\%), seguindo a tendência regional e nacional (sobe 33\% na AMP e 30\% em Portugal). Em 2015, um terço do pessoal ao serviço do Porto tinha ensino superior, o que representa 37\% do total da AMP e 7\% a nível nacional (apenas superado pelo concelho de Lisboa com $24 \%$ do pessoal ao serviço com ensino superior do total do país). O modelo de emprego do concelho carateriza-se por um forte peso do emprego público ( $21 \%$ do total de emprego do concelho, em 2015), concentrando 39\% do emprego público da área metropolitana e $19 \%$ da Região Norte.

Esta evolução da estrutura de emprego é também comprovada pela importância das profissões socialmente mais valorizadas ${ }^{2}$ no conjunto das profissões. Segundo os dados de 2011 do INE, a proporção de profissionais socialmente mais valorizados no concelho do Porto era de $40 \%$ (apenas superado pelo concelho de Lisboa com $42 \%)$, acima da média metropolitana e nacional, com $26 \%$ e $22 \%$, respetivamente.

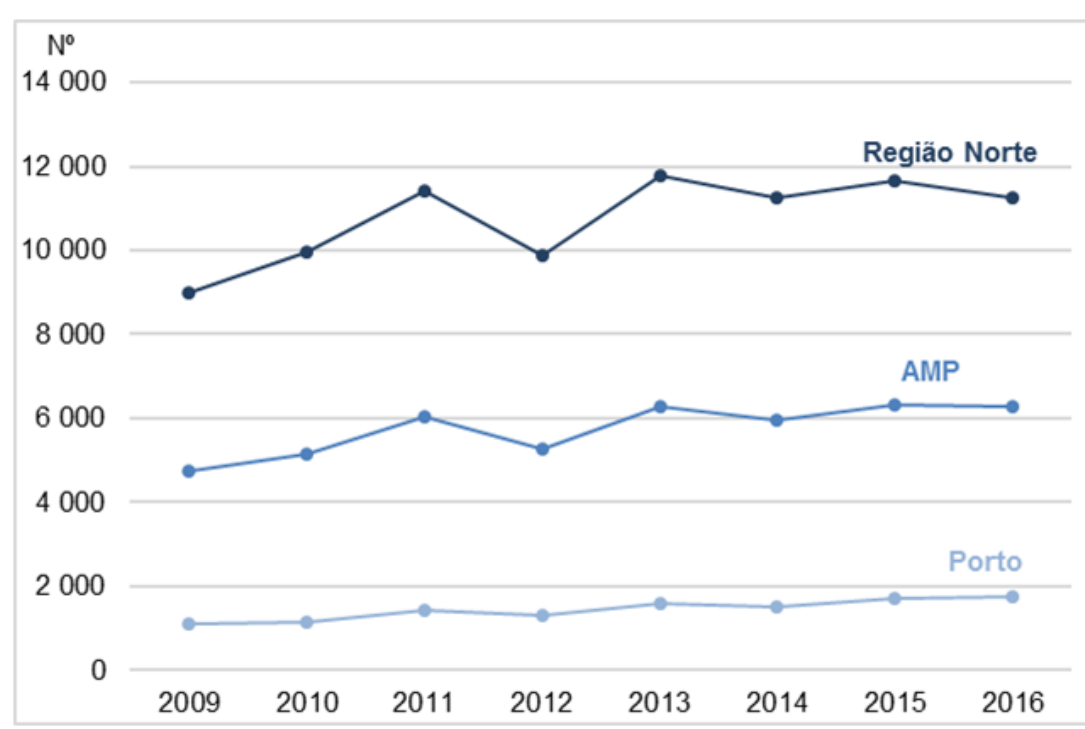

Gráfico 1 - Número de sociedades constituídas (2009-2016). Fonte: Elaboração própria; fonte de dados: PORDATA (2017).

\footnotetext{
${ }^{2}$ Indicador do INE que mede a importância das profissões mais valorizadas no conjunto das profissões (Classificação Nacional das Profissões, CNP). Incluem os representantes do poder legislativo e de órgãos executivos, dirigentes, diretores e gestores executivos (Grupo 1) e os especialistas das atividades intelectuais e científicas (Grupo 2).
} 


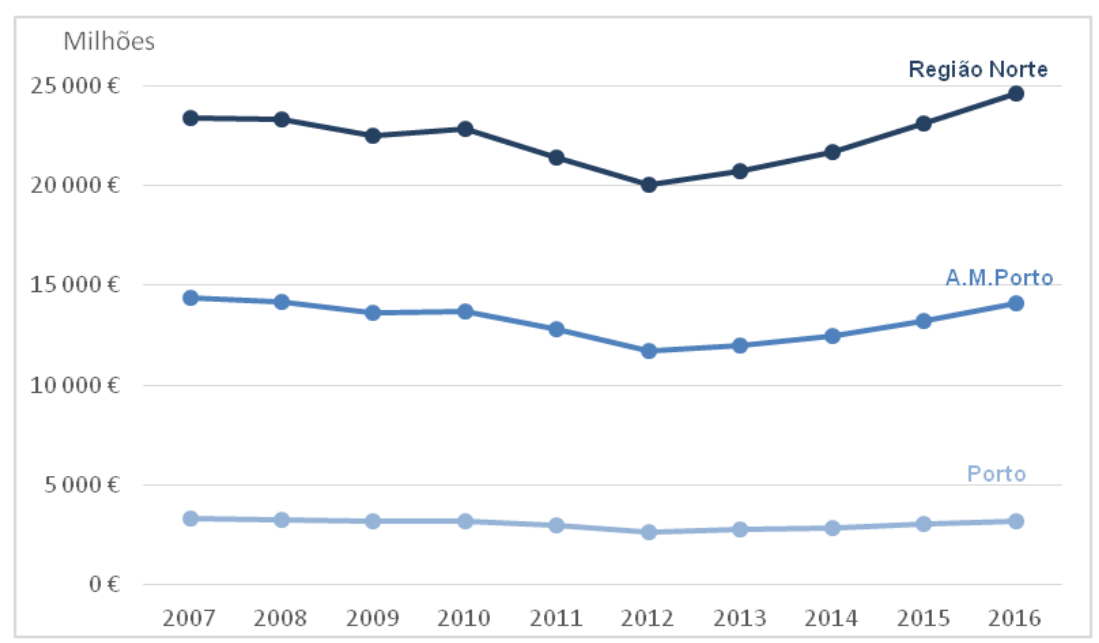

Gráfico 2 - Evolução do VAB (2007-2016). Fonte: Elaboração própria; fonte de dados: INE, Sistema de contas integradas das empresas (2016).

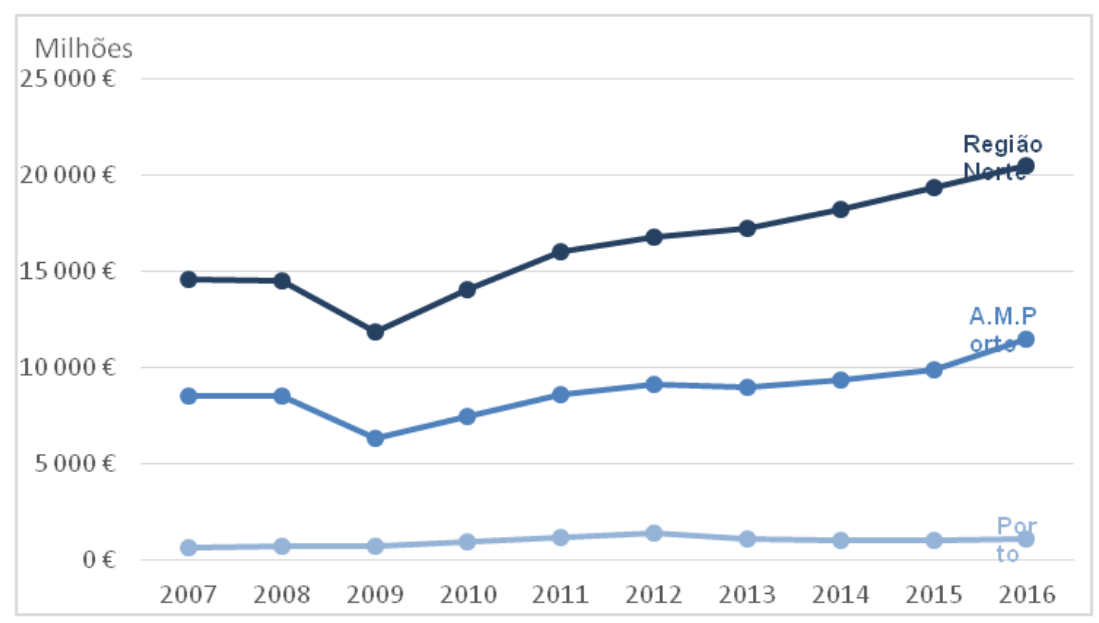

Gráfico 3 - Evolução das exportações de bens e produtos (2007-2015). Fonte: Elaboração própria; fonte de dados: INE, Estatísticas do Comércio Internacional de Bens (2015).

Quadro 2 - Pessoal ao Serviço e Emprego Público em 2015 e Pessoal ao Serviço com ensino superior (2007-2015).

\begin{tabular}{|l|l|l|}
\hline Âmbito Territorial & $\begin{array}{l}\text { Total Pessoal } \\
\text { ao Serviço } \\
2015\end{array}$ & $\begin{array}{l}\text { Total Em- } \\
\text { prego Públi- } \\
\text { co 2015 }\end{array}$ \\
\hline Portugal & 2771272 & 660686 \\
\hline Região Norte & 1002831 & 157770 \\
\hline AMP & 519452 & 80104 \\
\hline Porto & 116390 & 31061 \\
\hline \% Porto em PT & $4,2 \%$ & $4,7 \%$ \\
\hline \% Porto na R. Norte & $11,6 \%$ & $19,7 \%$ \\
\hline \% Porto na AMP & $22,4 \%$ & $38,8 \%$ \\
\hline
\end{tabular}

\begin{tabular}{|l|l|l|}
\hline $\begin{array}{l}\text { Taxa de Pessoal ao } \\
\text { Serviço com Ensino } \\
\text { Superior 2007 }\end{array}$ & $\begin{array}{l}\text { Taxa de Pessoal ao } \\
\text { Serviço com Ensino } \\
\text { Superior 2015 }\end{array}$ & $\begin{array}{l}\text { Variação relativa Pessoal } \\
\text { ao Serviço com Ensino } \\
\text { Superior 2007- } \\
2015\end{array}$ \\
\hline 12,90 & 19,18 & 30,1 \\
\hline 10,52 & 16,02 & 36,0 \\
\hline 13,19 & 19,59 & 33,2 \\
\hline 22,25 & 32,14 & 31,1 \\
\hline
\end{tabular}

Fonte: Elaboração própria; fonte de dados: GEP-MTSSS (2017); DGAEP (2016). 
Mudando de escala, em termos territoriais, verifica-se uma elevada concentração de estabelecimentos nas áreas mais consolidadas da cidade, isto é, na Baixa alargada, bem como na área da Boavista, ao longo de toda a Avenida da Boavista (nomeadamente em torno da Praça de Mouzinho de Albuquerque) (Figura 1). Por freguesias, destaca-se a União de Freguesias de Cedofeita, Santo Ildefonso, Sé, Miragaia, São Nicolau e Vitória, que representa 34\% do total de estabelecimentos da cidade. Seguindo-se Paranhos, Ramalde e a União de Freguesias de Lordelo do Ouro e Massarelos, embora com um peso percentual significativamente inferior (entre 13 a $15 \%$ por freguesia). Na situação mais desfavorável encontra-se a freguesia de Campanhã (6\% do total de estabelecimentos).

A estrutura empresarial do concelho, de acordo com a dimensão das empresas por número de trabalhadores, é dominada pelas empresas com menos de 10 empregados, que representam $68 \%$ do total de empresas com sede no Porto. O peso das pequenas e médias empresas (entre 10 e 250 trabalhadores) no tecido económico é muito inferior, abrangendo apenas $7 \%$ das empresas sediadas no concelho. É ainda de referir que $25 \%$ das empresas não têm ou não declararam empregados.

A concentração de pessoas empregadas acompanha, em termos gerais, a tendência espacial da localização dos estabelecimentos, sendo mais elevada na área central da cidade. Verifica-se pontualmente valores elevados de densidade, nomeadamente em Campanhã onde se localiza a Mota Engil com um número elevado de empregados, em Paranhos com o emprego do Hospital de S. João e do IPO, bem como pelo emprego concentrado em várias empresas na Zona Industrial de Ramalde (Figura 2). Por freguesias, a União de Freguesias de Cedofeita, Santo Ildefonso, Sé, Miragaia, São Nicolau e Vitória representava cerca de 35\% do total de pessoas empregadas no concelho. Seguia-se a freguesia de Paranhos (18\% do total do concelho) e as freguesias de Campanhã, do Bonfim e da União de Freguesias de Aldoar, Foz do Douro e Nevogilde registam o menor peso percentual de empregados (entre 7 a $9 \%$ por freguesia).

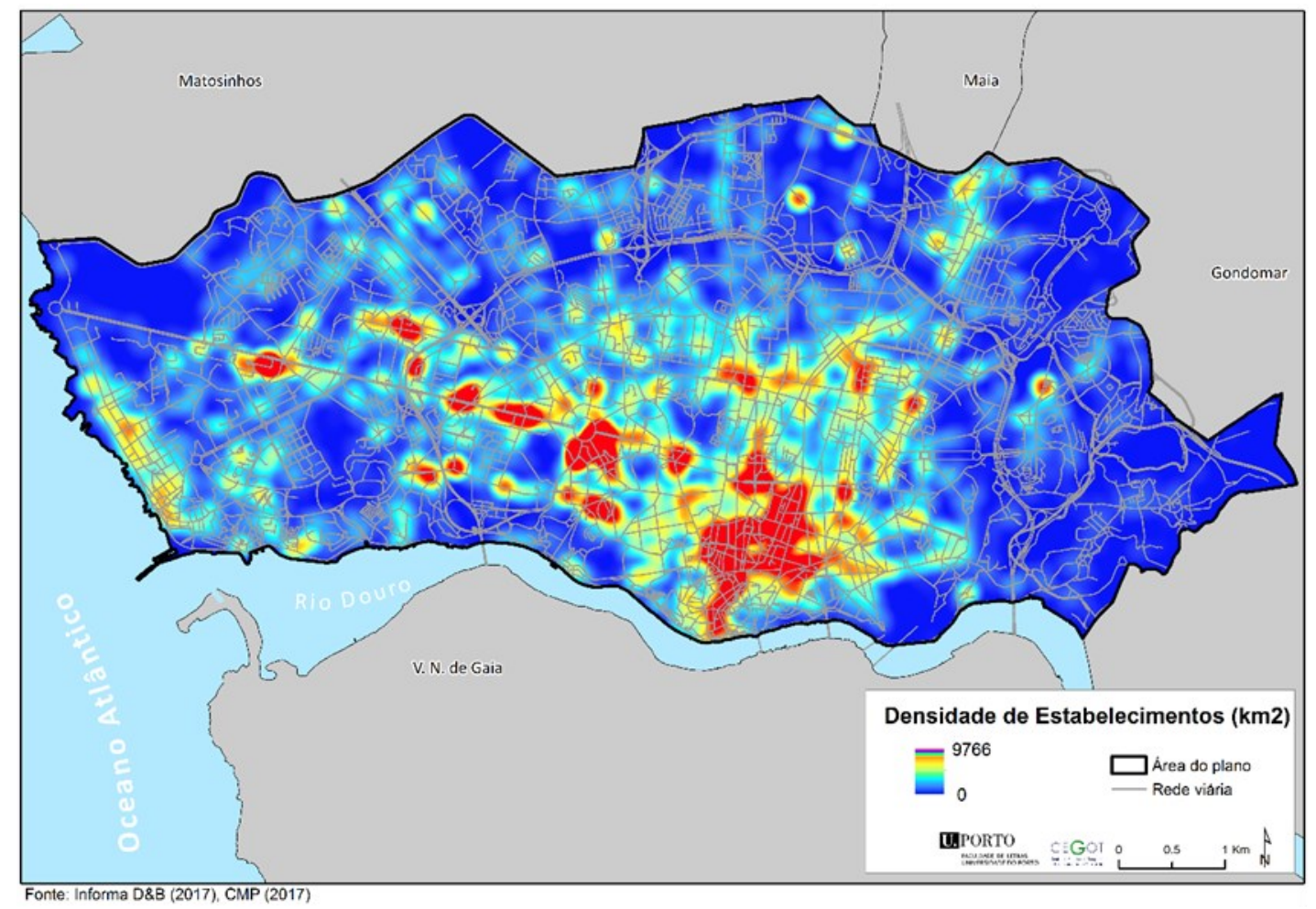

Figura 1 - Densidade de estabelecimentos no concelho do Porto. Fonte: Elaboração própria; fonte de dados: Informa $D \& B(2017)$. 


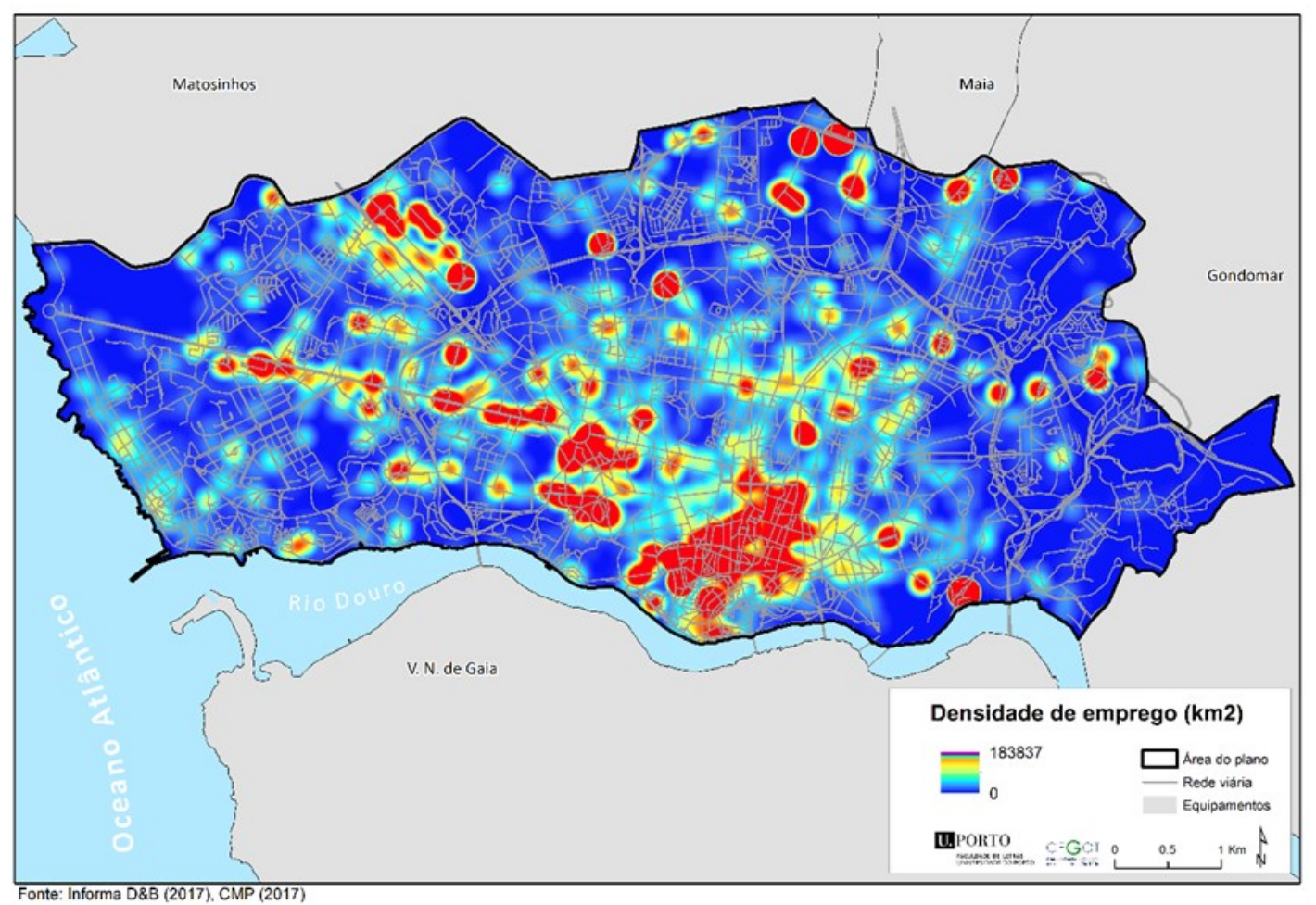

Figura 2 - Densidade de emprego no concelho do Porto. Fonte: Elaboração própria; fonte de dados: Informa D\&B (2017).

\subsection{Os domínios de especialização inteligente: identificação das atividades e distribuição espacial.}

Todos os domínios de especialização inteligente identificados no documento estratégico Norte 2020 (CCDRN, 2014) estão presentes no território da cidade do Porto. Estes correspondem a mais de um terço das empresas sediadas $(37,8 \%)$ e/ou com estabelecimento $(38,7 \%)$ no concelho do Porto. Representam $41,3 \%$ do emprego. O volume de vendas corresponde a 31,7\% do total do concelho. Por si só, os domínios de especialização inteligente são responsáveis por $43,8 \%$ do total das exportações com origem na cidade do Porto e por quase metade da riqueza (VAB) produzida no concelho do Porto $(47,81 \%)$.

Estes indicadores colocam desde já um problema: mais de $60 \%$ das empresas e dos estabelecimentos, mais de $50 \%$ do emprego, mais de $60 \%$ do volume de vendas, mais de $50 \%$ das exportações e da riqueza (VAB) da cidade do Porto não está contemplada nas atividades identificadas como pertencentes aos domínios de especialização inteligente definidos pelo documento Norte 2020 (RIS3). Todas essas atividades económicas, com um peso tão significativo na atividade económica da cidade, ficam excluídas das políticas de aplicação dos fundos comunitários? Será esta uma evidência da dificuldade de encaixar a estratégia de especialização inteligente na realidade que emana do território concreto?

Numa análise mais detalhada, constata-se que nem todos os oito domínios de especialização inteligente definidos pela estratégia Norte 2020 têm importância local. Existem três domínios de especialização inteligente que se constituem como grupo dominante. Esses domínios são:

- O domínio das Ciências da Vida e Saúde, que totaliza 19,4\% das sedes de empresas e 19,1\% dos estabelecimentos integrados na RIS3 e localizados no Porto, gerando uma fatia de 36,3\% do emprego nas atividades RIS3 do concelho e contribuindo com 42,7\% do volume de vendas, 9,7\% do volume de exportações e 40,5\% do VAB produzido pelo total das atividades RIS3 localizadas no Porto.

- O domínio do Capital Simbólico, Tecnologias e Serviços do Turismo, que totaliza 30,3\% das sedes de empresas e $29,2 \%$ dos estabelecimentos integrados na RIS3 e localizados no Porto, gerando uma fatia de $23,5 \%$ do emprego nas atividades RIS3 do concelho e contribuindo com $21 \%$ do volume de vendas, $26,8 \%$ do volume de exportações e 17,6\% do VAB produzido pelo total das atividades RIS3 localizadas no Porto.

- O domínio do Capital Humano e Serviços Especializados, que totaliza 35,6\% das sedes de empresas e $34,7 \%$ dos estabelecimentos enquadrados na RIS3 localizados no Porto, gerando uma fatia de $23,3 \%$ do emprego 
Quadro 3 - Empresas com sede no Porto, Exportações e VAB por domínios de especialização inteligente da RIS3 no concelho do Porto

\begin{tabular}{|c|c|c|c|c|c|c|c|c|c|}
\hline $\begin{array}{l}\text { Domínios da Especialização } \\
\text { Inteligente }\end{array}$ & $\begin{array}{l}N^{\circ} \text { Empre- } \\
\text { sas com } \\
\text { sede no } \\
\text { Porto }\end{array}$ & $\begin{array}{l}\text { \% Empre- } \\
\text { sas Sede } \\
\text { no total } \\
\text { RIS3 }\end{array}$ & $\begin{array}{l}\% \text { Empresas } \\
\text { Sede no } \\
\text { total do } \\
\text { Porto }\end{array}$ & $\begin{array}{l}\text { Total Exporta- } \\
\text { çốes }(€)\end{array}$ & $\begin{array}{l}\text { \% Exporta- } \\
\text { ções no } \\
\text { total RIS3 }\end{array}$ & $\begin{array}{l}\text { \% Exporta- } \\
\text { ções no } \\
\text { total do } \\
\text { Porto }\end{array}$ & Total VAB $(€)$ & $\begin{array}{l}\% \text { VAB } \\
\text { no total } \\
\text { RIS3 }\end{array}$ & $\begin{array}{l}\% \text { VAB } \\
\text { no total } \\
\text { do Porto }\end{array}$ \\
\hline $\begin{array}{l}\text { Capital Humano e Serviços } \\
\text { Especializados }\end{array}$ & 3632 & 35,56 & 13,44 & $147664172 €$ & 24,34 & 10,66 & $301312146 €$ & 23,92 & 11,44 \\
\hline $\begin{array}{l}\text { Capital Simbólico, Tecnologias } \\
\text { e Serviços do Turismo }\end{array}$ & 3099 & 30,34 & 11,47 & $162587869 €$ & 26,80 & 11,73 & $221982380 €$ & 17,63 & 8,43 \\
\hline Ciências da Vida e Saúde & 1983 & 19,41 & 7,34 & $58820933 €$ & 9,70 & 4,24 & $510441095 €$ & 40,53 & 19,38 \\
\hline Cultura, Criação e Moda & 1013 & 9,92 & 3,75 & $68107344 €$ & 11,23 & 4,91 & $116863630 €$ & 9,28 & 4,44 \\
\hline $\begin{array}{l}\text { Sistemas Avançados de Produ- } \\
\text { ção }\end{array}$ & 677 & 6,63 & 2,51 & $104454737 €$ & 17,22 & 7,54 & $139427810 €$ & 11,07 & 5,29 \\
\hline $\begin{array}{l}\text { Sistemas Agroambientais e } \\
\text { Alimentação }\end{array}$ & 458 & 4,48 & 1,69 & $143487973 €$ & 23,65 & 10,35 & $104450207 €$ & 8,29 & 3,97 \\
\hline Recursos do Mar e Economia & 193 & 1,89 & 0,71 & $4413389 €$ & 0,73 & 0,32 & $10365151 €$ & 0,82 & 0,39 \\
\hline $\begin{array}{l}\text { Indústrias da Mobilidade e } \\
\text { Ambiente }\end{array}$ & 62 & 0,61 & 0,23 & $3877032 €$ & 0,64 & 0,28 & $6601867 €$ & 0,52 & 0,25 \\
\hline Total Domínios RIS3 Porto(*) & 10215 & & & $606620936 €$ & & & $\begin{array}{l}1259434089 \\
€\end{array}$ & & \\
\hline Total Concelho Porto & 27023 & & & $\begin{array}{l}1385759900 \\
€\end{array}$ & & & $\begin{array}{l}2634105639 \\
€\end{array}$ & & \\
\hline $\begin{array}{l}\text { Peso dos Domínios da RIS3 no } \\
\text { total do concelho }\end{array}$ & 37,80 & & & 43,78 & & & 47,81 & & \\
\hline
\end{tabular}

$\left({ }^{*}\right)$ - Existem CAE que se repetem nos diferentes domínios da RIS3, pelo que o total não é o somatório dos oito domínios. O Total corresponde à soma das CAE incluídas nas RIS3

Fonte: Elaboração própria; fonte de dados: Informa D\&B (2017).

Quadro 4 - Empregados, Estabelecimentos e Volume de Negócios por domínios de especialização inteligente da RIS3 no concelho do Porto.

\begin{tabular}{|c|c|c|c|c|c|c|c|c|c|}
\hline Tipologia & $\begin{array}{l}\mathrm{N}^{\circ} \\
\text { Empre- } \\
\text { gados }\end{array}$ & $\begin{array}{l}\text { \% Em- } \\
\text { preg. no } \\
\text { total da } \\
\text { RIS3 } \\
\end{array}$ & $\begin{array}{l}\text { \% Empreg. } \\
\text { no total } \\
\text { do Porto }\end{array}$ & $\begin{array}{l}N^{\circ} \text { Esta- } \\
\text { bele- } \\
\text { cimentos }\end{array}$ & $\begin{array}{l}\% \text { Estabe- } \\
\text { lec. no } \\
\text { total da } \\
\text { RIS3 } \\
\end{array}$ & \begin{tabular}{|l|}
$\%$ Estabe- \\
lec. no \\
total do \\
Porto \\
\end{tabular} & $\begin{array}{l}\text { Volume de Ven- } \\
\text { das }(€)\end{array}$ & $\begin{array}{l}\text { \% Volume } \\
\text { de Vendas } \\
\text { no total da } \\
\text { RIS3 } \\
\end{array}$ & $\begin{array}{l}\text { \% Volume } \\
\text { de Vendas } \\
\text { no total do } \\
\text { Porto } \\
\end{array}$ \\
\hline Capital Humano e Serv. Especializados & 13481 & 23,26 & 9,41 & 3811 & 34,70 & 13,43 & $616227833 €$ & 17,31 & 5,53 \\
\hline $\begin{array}{l}\text { Capital Simbólico, Tecnologias e Servi- } \\
\text { ços do Turismo }\end{array}$ & 13632 & 23,52 & 9,51 & 3212 & 29,24 & 11,32 & $749767942 €$ & 21,06 & 6,73 \\
\hline Ciências da Vida e Saúde & 21035 & 36,29 & 14,68 & 2096 & 19,08 & 7,39 & $1519894664 €$ & 42,68 & 13,64 \\
\hline Cultura, Criação e Moda & 7275 & 12,55 & 5,08 & 1506 & 13,71 & 5,31 & $385406626 €$ & 10,82 & 3,46 \\
\hline Sistemas Avançados de Produção & 5517 & 9,52 & 3,85 & 712 & 6,48 & 2,51 & $352062777 €$ & 9,89 & 3,16 \\
\hline $\begin{array}{l}\text { Sistemas Agroambientais e Alimenta- } \\
\text { ção }\end{array}$ & 2285 & 3,94 & 1,59 & 485 & 4,42 & 1,71 & $156132332 €$ & 4,38 & 1,40 \\
\hline Recursos do Mar e Economia & 806 & 1,39 & 0,56 & 205 & 1,87 & 0,72 & $66703732 €$ & 1,87 & 0,60 \\
\hline Indústrias da Mobilidade e Ambiente & 460 & 0,79 & 0,32 & 68 & 0,62 & 0,24 & $35458862 €$ & 1,00 & 0,32 \\
\hline Total Domínios RIS3 Porto (*) & 57958 & & & 10984 & & & $3560836064 €$ & & \\
\hline Total Concelho Porto & 143316 & & & 28380 & & & $11139170702 €$ & & \\
\hline $\begin{array}{l}\text { Peso dos Domínios da RIS3 no total } \\
\text { do concelho }\end{array}$ & 40,44 & & & 38,70 & & & 31,97 & & \\
\hline
\end{tabular}

Fonte: Elaboração própria; fonte de dados: Informa D\&B (2017).

nas atividades RIS3 do concelho e contribuindo com 17,3\% do volume de vendas, $24,3 \%$ do volume de exportações e $23,9 \%$ do VAB produzido pelo total das atividades RIS3 localizadas no Porto.

Segue-se um grupo de mais três domínios, cujo peso na totalidade das atividades enquadradas na RIS3 localizadas no Porto é significativo em alguns dos indicadores analisados:

- O domínio da Cultura, Criação e Moda que totaliza 9,9\% das sedes de empresas e 13,7\% dos estabelecimentos integrados na RIS3 localizados no Porto, gerando uma fatia de $12,5 \%$ do emprego nas atividades RIS3 do concelho e contribuindo com $10,8 \%$ do volume de vendas, $11,3 \%$ do volume de exportações e $9,3 \%$ do VAB produzido pelo total das atividades RIS3 localizadas nesta cidade. 
- O domínio dos Sistemas Avançados de Produção que totaliza 6,6\% das sedes de empresas e 6,5\% dos estabelecimentos integrados na RIS3 localizados no Porto, gerando uma fatia de 9,5\% do emprego nas atividades RIS3 do concelho e contribuindo com 9,9\% do volume de vendas, 17,2\% do volume de exportações e 11,1\% do VAB produzido pelo total das atividades RIS3 localizadas nesta cidade.

- O domínio dos Sistemas Agroambientais e Alimentação, que totaliza 4,5\% das sedes de empresas e 4,4\% dos estabelecimentos integrados na RIS3 localizados no Porto, gerando uma fatia de 3,9\% do emprego nas atividades RIS3 do concelho e contribuindo com $4,4 \%$ do volume de vendas, $23,7 \%$ do volume de exportações e $8,3 \%$ do VAB produzido pelo total das atividades RIS3 localizadas nesta cidade.

Por último, observa-se um grupo composto por dois domínios cujo peso na totalidade das atividades enquadradas na RIS3 localizadas no Porto é muito residual: o domínio dos Recursos do Mar e Economia, que totaliza 1,9\% das sedes de empresas e 1,9\% dos estabelecimentos integrados na RIS3; o domínio das Indústrias da Mobilidade e Ambiente, que totaliza $0,6 \%$ das sedes de empresas e $0,6 \%$ dos estabelecimentos integrados na RIS3.

Em termos territoriais (figura 3), os estabelecimentos dos domínios de especialização inteligente exibem um padrão mais concentrado na Baixa e no Centro Histórico, estendendo-se até à rotunda da Boavista, e prolongando-se até sensivelmente metade da Avenida da Boavista. Paralela à Avenida da Boavista emerge uma concentração linear, estruturada pela Avenida do Bessa. Na Asprela, emergem três polos aglutinados em torno do Hospital de S. João, IPO e UPTEC. Na parte oriental da cidade, correspondente a grande parte da freguesia de Campanhã, observa-se uma redução significativa da densidade de estabelecimentos face ao padrão de distribuição caraterístico da cidade do Porto.

A figura 4 mostra a distribuição territorial dos estabelecimentos por domínio de especialização inteligente, revelando um padrão cuja localização e densidade é variável.

Em síntese, por um lado, os domínios de especialização inteligente representam uma fatia significativa do tecido empresarial localizado na cidade do Porto, assim como do emprego, vendas, exportação e da riqueza aí produzida. Por outro lado, o Porto mostra um perfil que privilegia alguns dos domínios da RIS3.

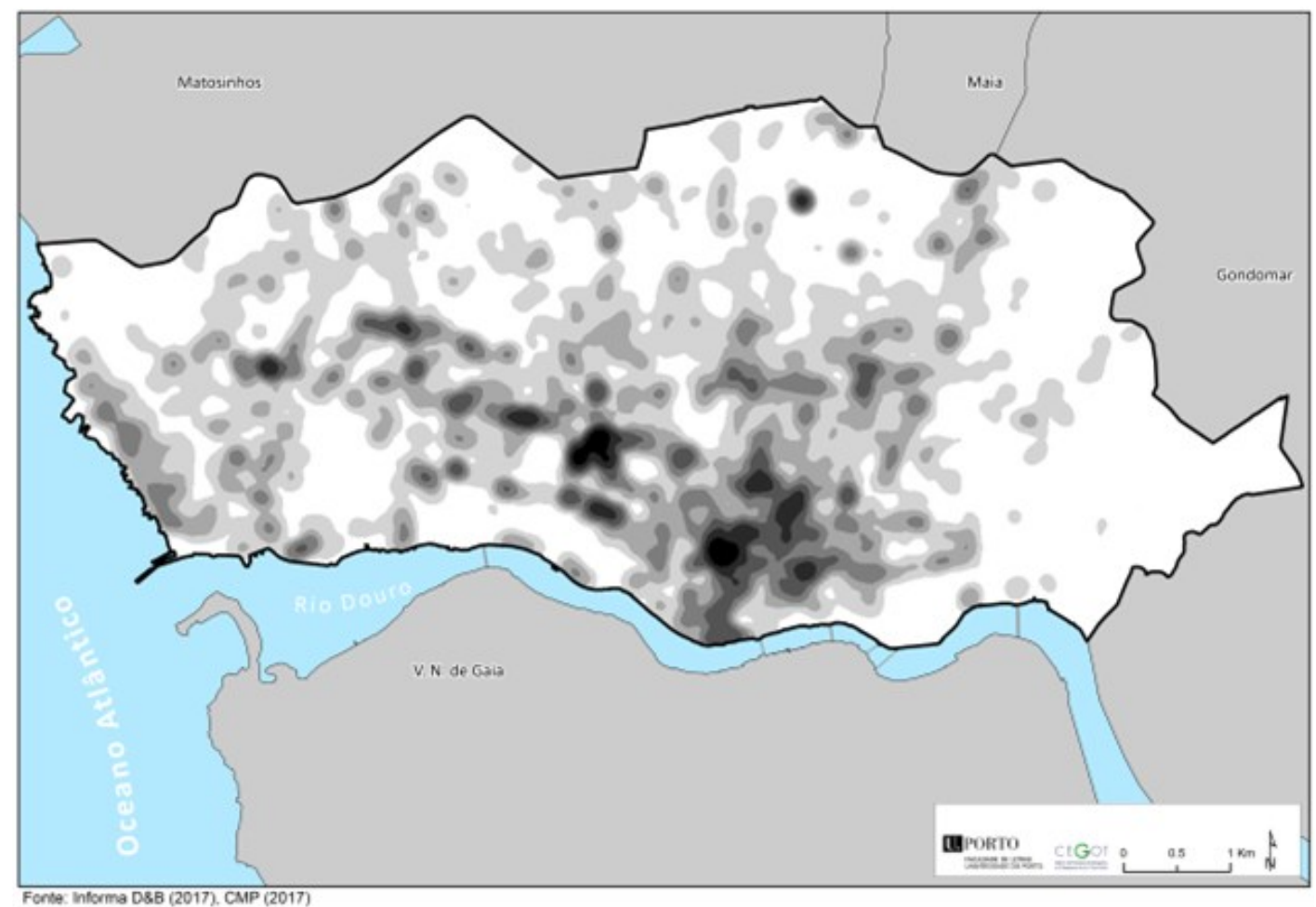

Figura 3 - Densidade e Modelo de distribuição de estabelecimentos do concelho do Porto enquadrados nos domínios da especialização inteligente. Fonte: Elaboração própria; fonte de dados: Informa D\&B (2017). 
Ciências da Vida e Saúde

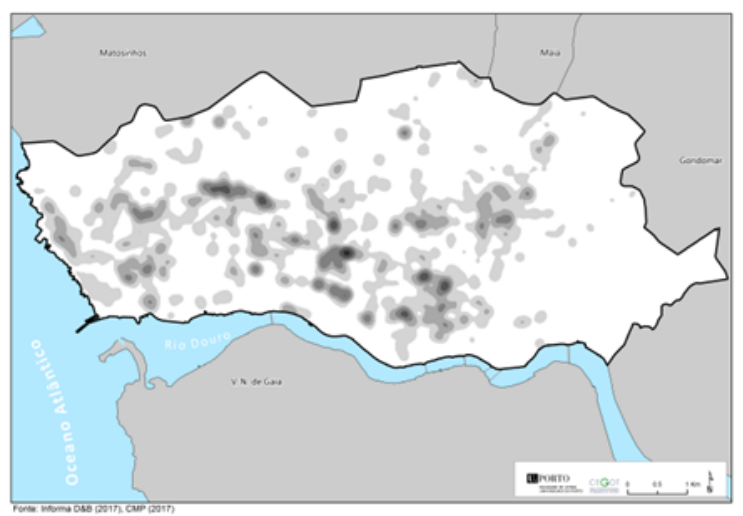

Capital Humano e Serviços Especializado

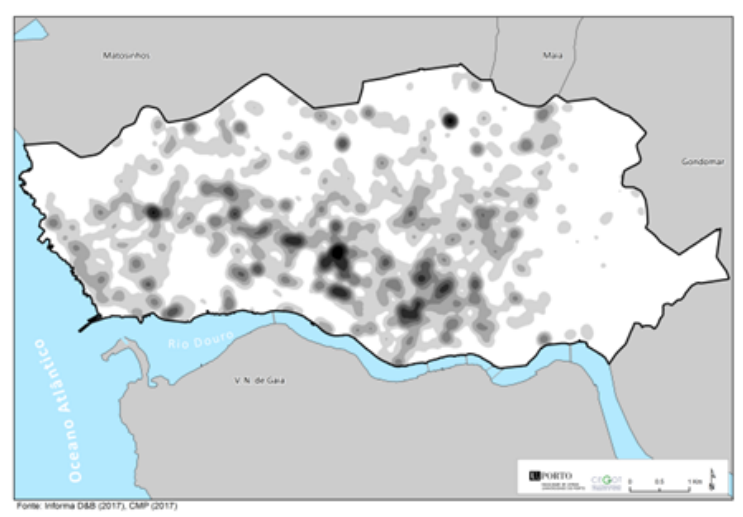

Sistemas Avançados de Produção

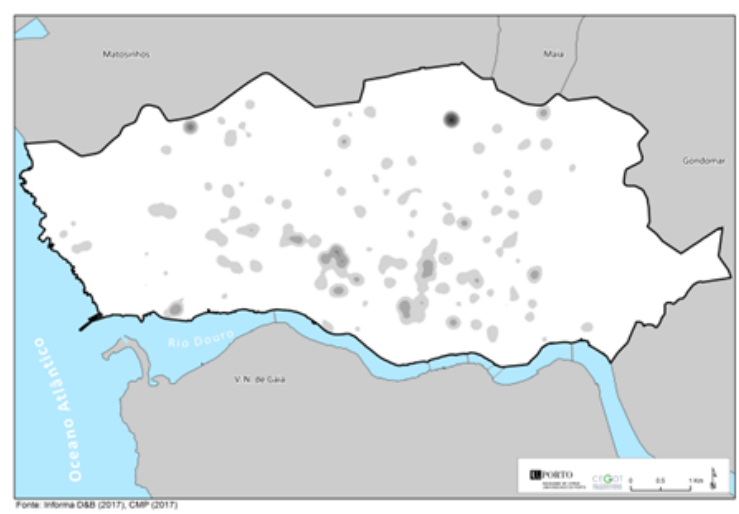

Capital Simbólico, Tecnologias e Serviços do Turismo

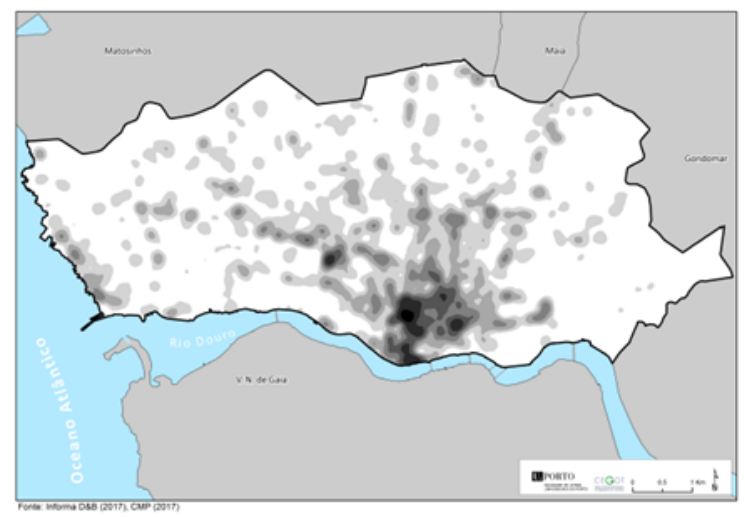

Cultura, Criação e Moda

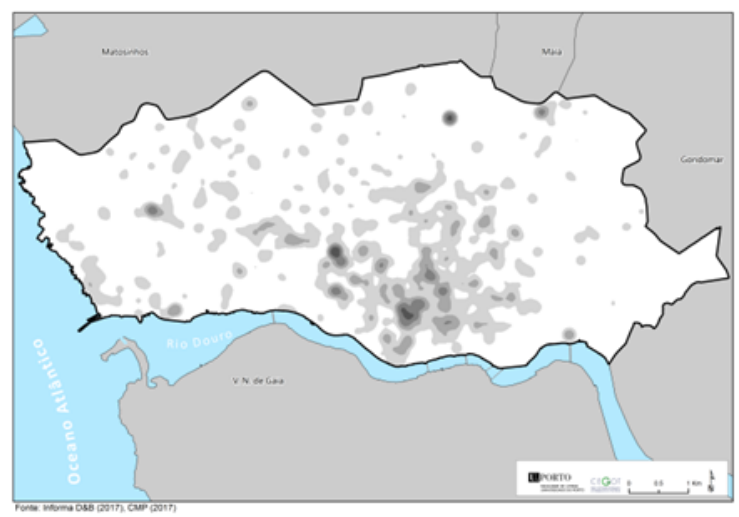

Sistemas Agroambientais e Alimentação

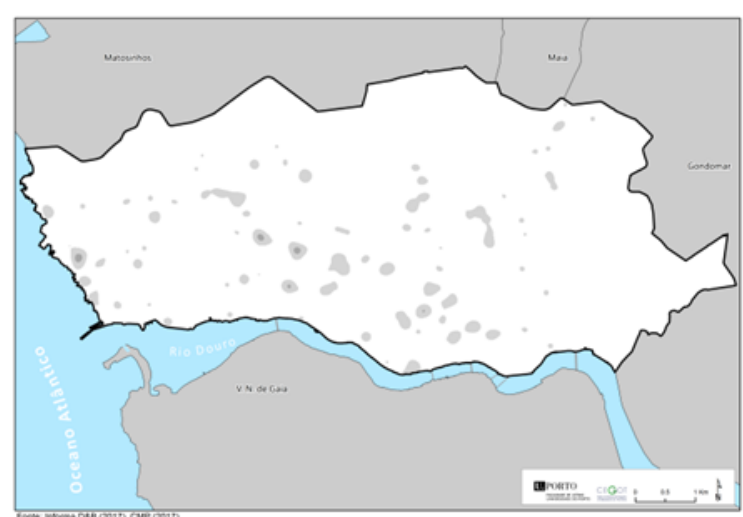

Figura 4 - Densidade e Modelo de distribuição dos estabelecimentos do concelho do Porto enquadrados nos diferentes domínios da especialização inteligente.

\section{CONCLUSÃO}

O diagnóstico elaborado no âmbito do PDM, com base nos domínios de especialização inteligente, permitiu fazer uma reflexão estratégica local, com possíveis implicações em matéria de ordenamento do território:

a) A localização no Porto de um tecido económico direcionado para os domínios de especialização inteligente identificados no documento estratégico Norte 2020, atesta a presença de um amplo leque de competências estratégicas instaladas na cidade. Tal significa que existem recursos que potenciam os processos de fertiliza- 
ção cruzada de conhecimento, com potencial inovador. A criação de ecossistemas favoráveis ao empreendedorismo e inovação que facilitem a polinização cruzada e a troca de conhecimento é uma via para dinamizar a vitalidade económica da cidade. O PDM deve prever a possibilidade de instalação de infraestruturas tecnológicas, de incubação, e de serviços e equipamentos partilhados, e de empresas pertencentes aos domínios de especialização já presentes no concelho. Deve ainda afetar usos de solo dirigidos à instalação de indústrias e serviços, intensivos em conhecimento e fomentar a permanência destas atividades económicas no concelho, ao longo do seu ciclo de vida, criando, para tal, tipologias de uso de solo que possibilitem o crescimento das instalações industriais no concelho.

b) A cidade é ela mesma um ecossistema que pode favorecer a criação de redes locais e a criação de ambiente vibrantes favoráveis à produção económica. A análise dos padrões de distribuição destas atividades económicas revela a tendência para a concentração na Baixa, Rotunda da Boavista e envolvente, Avenida da Boavista e Asprela. A colocalização nestes hot-spots pode favorecer a criação de redes interpessoais e interorganizacionais, incrementando os processos de buzz urbano, a troca de conhecimento e a emergência de processos de inovação e produção económica, pelo que a estratégia de ordenamento do território deve favorecer a instalação de novas atividades ligadas aos diferentes perfis de especialização inteligente.

c) Apesar da abrangência das capacidades e competências económicas instaladas na cidade, a análise efetuada revela que existem três domínios de especialização inteligente mais fortes (Ciências da Vida e Saúde; Capital Simbólico, Tecnologias e Serviços do Turismo; e Capital Humano e Serviços Especializados). Estas são atividades intensivas em conhecimento (analítico, sintético e simbólico), que se sustentam em capital humano com competências altamente especializadas, normalmente bem remuneradas. Estes são trabalhadores do conhecimento e classes criativas com expetativas de qualidade de vida e bem-estar que apontam para padrões médio -altos e altos. As políticas urbanas que favoreçam a atração e fixação (para residir e trabalhar) deste capital na cidade (política de uso do solo, de habitação, de qualificação do espaço público ou as amenidades urbanas e outras externalidades positivas) contribuem para aumentar a dinâmica económica da cidade. Deve ainda apostar em ações de marketing territorial dirigidas à captação de empresas e serviços intensivos em conhecimento e baseados em capital humano qualificado, para reforçar a atratividade nacional e internacional do concelho para os serviços intensivos em conhecimento.

Mas esta experiência também permitiu constatar que uma estratégia de desenvolvimento e ordenamento do território só dirigida às empresas de especialização inteligente iria excluir uma fatia muito significativa das atividades económicas da cidade (mais de $60 \%$ das empresas e estabelecimentos, do emprego, do volume de vendas, das exportações e da riqueza da cidade). Esta observação reforça também a necessidade de se refletir sobre as políticas económicas de base territorial para outros sectores, pois a estratégia de especialização inteligente nem sempre se encaixa na diversidade de atividades económicas existentes, justificando a necessidade de um maior enfoque no território. O risco de exclusão de uma fatia tão significativa de atividades económicas da estratégia de especialização inteligente deve ser acautelado.

\section{BIBLIOGRAFIA}

BALLAND, P.-A., BOSCHMA, R., CRESPO, J., \& RIGBY, D. L. (2018). Smart specialization policy in the European Union: relatedness, knowledge complexity and regional diversification. Regional Studies .

BARCA, F., MCCANN, P., \& RODRÍGUEZ POSE, A. (2012). The Case for Regional Development Intervention: Place-Based Versus Place-Neutral Approaches. Journal of Regional Science, 52 (1), 134-152.

BEAVERSTOCK, J. V.; FAULCONBRIDGE, J. R.; HOYLER, M. (2011). Globalization and the City. In Leyshon, A.; Roger, L.; McDowell, L.; Sunley, P. (Eds.).The SAGE Handbook of Economic Geography. SAGE Publications Ltd., 189-201.

BOSCHMA, R. (2010). The Aims and Scope of Evolutionary Economic Geography. In Boschma, R; Martin, R. (Eds.).The Handbook of Evolutionary Economic Geography. Edward Elgar, 5-39.

CAPELLO, R., \& KROLL, H. (2016). From theory to practice in smart specialization strategy: emerging limits and possible future trajectories. European Planning Studies , 24 (8), 1393-1406.

CE (Março 2014). Política de Coesão 2014-2020: Desenvolvimento Urbano Sustentável Integrado. (978-92-79-37138-7). Disponível em: http://ec.europa.eu/regional_policy/sources/docgener/informat/2014/urban_pt.pdf.

DGT. (2018). PNPOT - Alteração: Diagnóstico (versão para discussão pública). Lisboa: DGT.

ESPON (15/12/2010). FOCI: Future Orientations for Clties. Applied Research 2013/1/1. Final Report | Version 15/ 
December/2010. Disponível em: http://www.espon.eu/export/sites/default/ Documents/Projects/AppliedResearch/ FOCl/FOCI_final_report_20110111.pdf.

EUROPEAN-COMMISSION. (2017, novembro 24). SMART SPECIALISATION PLATFORM. Retrieved maio 2, 2018, from http://s3platform.jrc.ec.europa.eu/

GULC, A. (2015). Analysis of Methodological Approach to Identify Smart Specialization on the Example of Polish Regions. Procedia - Social and Behavioral Sciences , 213, 817-823.

IAPMEI; FCT; ANI; COMPETE. (2014). Estratégia de linvestigação e Inovação para uma Especialização Inteligente 2014-2020. Lisboa: IAPMEI; FCT; ANI; COMPETE.

KEMPTON, L. (2015). Delivering smart specialization in peripheral regions: the role of Universities. Regional Studies, Regional Science , 2 (1), 489-496.

LEI N. ${ }^{\circ}$ 31/2014 , de 30 de maio. Diário da República : N. ${ }^{\circ}$ 104/2014, Série I (2014). Acedido a 02 mai. 2018. Disponível em www.dre.pt.

MARQUES, T. (2004). Portugal na transição do século: retratos e dinâmicas territoriais. Porto: Edições Afrontamento.

MARQUES, T. S., \& QUEIRÓS, J. P. (2017). AMP 2020 Crescimento Inteligente. Casal de Cambra: Caleidoscópio.

MARQUES, T. S., SANTOS, H., \& RIBEIRO, P. (2016). Especialização Inteligente: as complementaridades relacionais da inovação ancorada nas macrorregiões de Lisboa e do Porto. XV Coloquio Ibérico de Geografía.Retos y tendencias de la Geografía Ibérica (pp. 1210-1221). Murcia: Universidad de Murcia-AGE-APG.

MARQUES, T., \& SANTOS, H. (2013). Lugares e redes de inovação na área metropolitana do Porto. Geografia: Revista da Faculdade de Letras da Universidade do Porto , 2 (III), 203-225.

MAXIMILIAN, B., BIERINGER, L., KNAUPP, M., WITTEMAIER, J., \& WRUCK, A. (2016). Towards a Smart Specialization Strategy for Haifa, Israel. Munich Personal RePEc Archive - Heidelberg University , 1-63.

MCCANN, P., \& ORTEGA-ARGILÉS, R. (2013). Smart Specialization, Regional Growth and Applications to European Union Cohesion Policy. Regional Studies , 49 (8), 1291-1302.

MENDES, J. F. G. (2011). O Futuro das Cidades. Coimbra: Edições Minerva.

NALDI, L., NILSSON, P., WESTLUND, H., \& WIXE, S. (2015). What is smart rural development? Journal of Rural Studies , 40, 90 $-101$.

NIJKAMP, P.; KOURTIT, K. (2013). The "New Urban Europe": Global Challenges and Local Responses in the Urban Century. European Planning Studies, 21(3), 291-315. doi:10.1080/09654313.2012.716243.

NOVOSÁK, J., HÁJEK, O., ZAHRADNÍK, P., \& NEKOLOVÁ, J. (2013). On Some Aspects of Territorial Competitiveness: Smart Specialization in the Zlín 2020 Strategy. Journal of Competitiveness , 5 (3), 3-13.

RIBEIRO, J. M., \& FERRÃO, J. (. (2014). Noroeste Global. Lisboa: Fundação Calouste Gulbenkian.

RIBEIRO, J. M., MOURA, F., \& CHORINCAS, J. (2015). Uma Metrópole para o Atlântico. Lisboa: Fundação Calouste Gulbenkian.

SANDU, S. (2012). Smart specialization concept and the status of its implementation in Romania. Procedia Economics and Finance , 3, 236-242.

SANTOS, H., \& MARQUES, T. S. (2013). Lugares e redes de conhecimento na área metropolitana do Porto. Geografia: Revista da Faculdade de Letras da Universidade do Porto , 2 (III), 179-202. 